\title{
Yem Bezelyesi ve Tritikale Karışımlarında Karışım Oranları ile Biçim Dönemlerinin Ot Verimine Etkileri
}

\section{Seyithan SEYDOŞOĞLU ${ }^{* 1}$ (D) Gökhan GELIR ${ }^{2}$ (D), Belgizar AYANA ÇAM ${ }^{2}$ (i)}

\author{
${ }^{1}$ Siirt Üniversitesi Ziraat Fakültesi Tarla Bitkileri Bölümü, Siirt \\ ${ }^{2}$ GAP Uluslararası Tarımsal Araştırma ve Eğitim Merkezi Müdürlüğü, Diyarbakır
}

\begin{abstract}
Öz: Çalışmanın amacı, tritikale (x Triticosecale Wittmack) ile yem bezelyesi (Pisum sativum L.) karışımlarında, karışım oranı ve biçim dönemlerinin ot verimine etkilerini belirlemektir. Deneme, tesadüf bloklarında bölünmüş parseller deneme deseninde 3 tekerrürlü olarak kurulmuştur. Biçim dönemleri ana parselleri, karışım oranı ise alt parselleri oluşturmuştur. Araştırmada biçim dönemlerini, karışımlarda yer alan tritikalenin başaklanma ve süt olum dönemi olmak üzere 2 farklı dönem oluşturmuştur. Yalın olarak \%100 yem bezelyesi (YB) ve tritikale (T), karışım oranları ise \%75YB + \%25T, \%50 YB + \%50 T, \%25 YB + \%75 T'den oluşmaktadır. Çalışmada, biçim dönemleri geciktikçe ana sap uzunluğu, bitki boyu, yeşil ve kuru ot verimi değerleri artarken, kuru ve yeşil otta yem bezelyesi oranı değerlerinde azalış meydana gelmiştir. Karışımlarda yer alan tritikale oranı arttıkça, yeşil ve kuru ot veriminde istatistiki olarak artış meydana gelmiştir. Benzer şekilde, karışımlarda yer alan yem bezelyesi oranı arttıkça kuru ve yeşil otta yem bezelyesi oranında da artış meydana gelmiştir. Bir yıllık sonuçlara göre; ot verimi yönünden $\% 25$ YB +\%75 T karışımı diğer karışımlara göre daha üstün bulunmuştur.
\end{abstract}

Anahtar Kelimeler: yeşil ot, alan eşdeğerlik, botanik kompozisyon

\section{Effects of Mixture Ratio And Harvest Periods on Yield of Forage Pea and Triticale Mixtures}

\begin{abstract}
The aim of this study was to determine the effects of mixture ratio and harvest periods on hay yield of forage pea (Pisum sativum L.) and triticale ( $x$ Triticosecale Wittmack) mixtures. The study was carried out with 3 replication according to the experimental design of divided parcels in random blocks. Harvest periods were main parcels and mixture ratios were sub-parcels. Harvests were conducted in two differenet periods; spike emergence and milk period of seeds of triticale. Mixture ratios were $100 \%$ forage pea; $75 \%$ forage pea $+25 \%$ triticale, $50 \%$ forage pea $+50 \%$ triticale, $25 \%$ forage pea $+75 \%$ triticale and $100 \%$ triticale. While plant height, main stem length, green and dry grass yield as time of harvest were increased, dry and green grass forage pea ratio were decreased. As the ratio of triticale in the mixtures increased, there was a statistically significant increase in green and dry grass yield. Similarly, as the proportion of forage pea in the mixtures increased, the rate of forage pea increased in dry and green grass. According to one-year results; $25 \%$ YB $+75 \% T$ mixture was found to be superior to the other mixtures.
\end{abstract}

Keywords: herbage yield, land equivalent, botanical composition

\section{GíRiş}

Yem bitkilerinden tek yıllık olan baklagillerin tahıllarla karışım halinde yetiştirilmesi dünyada uzun yıllardan beri çok fazla kullanılan (Mariotti ve ark., 2009), ülkemizde ise her geçen gün benimsenen bir ekim yöntemi olmuştur. Baklagiller ve buğdaygillerin karışık ekilmesinin birçok avantajları vardır. Bunlardan en önemlileri karışık ekimlerde verim baklagillerin yalın ekilmesine göre daha yüksek olmaktadır (Ghanbari-Banjar ve Lee, 2003).

Karışık yem bitkileri ile ilgili yapılan çalışmalar incelendiğinde; Yıldırım ve Özaslan-Parlak (2016) farklı oranlarda karıştırılan tritikale ile yem bezelyesi çalışmalarında, karışımdaki tritikale oranı artıkça yeşil ve kuru ot verimlerinin arttığını bildirmişlerdir. Kavut ve ark. (2014) karışım oranı ve hasat zamanlarının bazı tek yılık baklagil yem bitkileri ile İtalya tek yıllık çim karışımlarında, hasat zamanının gecikmesi ile yeşil ot verimi ile kuru madde verimlerinin önemli ölçüde artığını, karışımdaki baklagil oranı artıkça yeşil otta baklagil oranının artığını bildirmişlerdir. Kocer ve Albayrak (2012) farklı oranlarda karıştırılan yulaf ve bezelye karışımında en yüksek yeşil ot $\% 65$ yulaf + \%35 bezelye karışımından elde edildiğini rapor etmişlerdir. Mihailoviç ve ark. (2011) sekiz farklı tahılın bezelye ile karışımında en yüksek verim tahılların \%55 + bezelyenin \%45 oranında tespit edildiğini bildirmişlerdir. Pereira-Crespo ve ark. (2010) farklı oranlarda karıştırılan bezelye ile tritikale karışımlarında, karışımdaki bezelye tohumu miktarı artıkça kuru madde miktarının da azaldığını bildirmişlerdir. Macar fiğ, tritikale, macar fiğ + tritikale karışımlarının farklı gelişim dönemlerinde, saf olarak yetiştirilen tritikalenin saf olarak yetiştirilen macar fiğ ve macar fiğ + tritikale karışımlarından daha yüksek verime sahip olduğu ve daha hızlı gelişim gösterdiği görülmüştür (Işık ve ark., 2013).

$\mathrm{Bu}$ çalışmanın amacı, yem bezelye (Pisum sativum L.) ve tritikale (x Triticosecale Wittmack) karışımlarında karışım oranları ile biçim dönemlerinin ot verimi üzerine etkilerini belirlemektir.

Sorumlu Yazar: seyithanseydosoglu@siirt.edu.tr

Geliş Tarihi: 19 Ağustos 2019

Kabul Tarihi: 6 Nisan 2020 
Yem Bezelyesi ve Tritikale Karışımlarında Karışım Oranları ile Biçim Dönemlerinin Ot Verimine Etkileri

\section{MATERYAL VE YÖNTEM}

Araştırmanın bitki materyalleri, yem bezelyesinin (Pisum sativum L.) Gap Pembesi çeşidi ile tritikalenin (xTriticosecale Wittmack) Karma 2000 çeşidi oluşturmuştur.

Araştırma, Diyarbakır koşullarında 2016-2017 yılı vejetasyon döneminde GAP UTAEM'ın deneme arazisinde yürütülmüştür. Denemenin yürütüldüğü döneme ait bazı iklim verileri Çizelge 1 'de verilmiştir.

Deneme yeri toprağı, 0-30 cm derinlikte killi-tınlı bünyeye sahip olup, $\mathrm{pH}: 7.75$, organik madde: $\% 0.68$ ve tuz sorunu olmayan bir yapıya sahiptir. Gerek iklim ve gerekse toprak özellikleri, araştırma konusu olan yem bezelyesi ve tritikale tarımı açısından kısıtlayıcı herhangi bir etki göstermemektedir.

Araştırma, tesadüf bloklarında bölünmüş parseller deneme desenine göre 3 tekerrürlü olarak yürütülmüştür. Biçim dönemleri ana parselleri, karışım oranları ise alt parselleri oluşturmuştur. Araştırmada biçim dönemlerini, karışımlarda yer alan tritikalenin başaklanma ve süt olum dönemi olmak üzere 2 farklı dönem oluşturmuştur. Yalın olarak YB ve T, karışım oranları ise \%75 YB + \%25 T, \%50 YB + \%50 T, \%25 YB + \%75 T'den oluşmuştur.
Her parsel $6 \mathrm{~m}$ boyunda, 10 sıraya, $20 \mathrm{~cm}$ sıra aralığında, markörle açılarak ve karışım türleri aynı sıraya karışık olarak tahıl mibzeri ile ekilmiştir. Ekimden önce parsellere $4 \mathrm{~kg} / \mathrm{da}$ saf azot ve $10 \mathrm{~kg} / \mathrm{da}$ saf fosfor tamamlanacak şekilde diamunyum fosfat gübresi uygulanmıştır (Kır, 2014). Ekimde, saf olarak yem bezelyesinin $10 \mathrm{~kg} / \mathrm{da}$ ve tritikalenin $22 \mathrm{~kg} / \mathrm{da}$ ekim normu dikkate alınmıştır. Hasatta her parselin kenarından 2 sıra ve parsel başlarından $0.5 \mathrm{~m}$ kenar tesiri olarak bırakılarak ve her parselde net $1.6 \times 5=8 \mathrm{~m}^{2}$ alanda hasat yapılmıştır.

Denemede, tritikale bitki boyu, yem bezelyesi ana sap uzunluğu, yeşil otta yem bezelyesi oranı, kuru otta yem bezelyesi oranı, yeşil ot verimi, kuru ot verimi ve alan eşdeğerlik oranı gibi özellikler incelenmiştir. Çizelgelerde ilgili özelliklere ait araştırma sonuçları sunulmuş ve istatistiksel olarak analizleri, JUMP adlı hazır paket programı kullanılarak yapılmıştır (Kalaycı, 2005). Bir yıllık ortalama değerlere göre düzenlenen çizelgelerdeki En Küçük Önemli Fark (LSD, \%5) değerleri, her çizelgenin alt bölümünde verilmiş ve önemsiz bulunanlar ö.d. ile simgelendirilmiştir.

Çizelge 1. Diyarbakır iline ait bazı iklim verileri (Anonim, 2019)

\begin{tabular}{lllll}
\hline Aylar & \multicolumn{2}{l}{ Ortalama Sıcaklık $\left({ }^{\circ} \mathrm{C}\right)$} & Yağış $(\mathrm{mm})$ & Uzun Yıllar \\
\cline { 2 - 5 } & $2016-2017$ & Uzun Yıllar & $2016-2017$ & 4.1 \\
\hline Eylül & 24.2 & 24.8 & 5.2 & 34.7 \\
Ekim & 18.8 & 17.2 & 13.6 & 51.8 \\
Kasım & 8.2 & 9.2 & 52.0 & 71.4 \\
Aralık & 2.4 & 4.0 & 135.6 & 68.0 \\
Ocak & 1.5 & 1.8 & 20.6 & 68.8 \\
Şubat & 1.5 & 3.5 & 3.8 & 67.3 \\
Mart & 9.4 & 8.5 & 90.2 & 68.7 \\
Nisan & 12.8 & 13.8 & 98.8 & 41.3 \\
Mayıs & 18.8 & 19.3 & 30.6 & 7.9 \\
Haziran & 26.9 & 26.3 & 2.6 & 484.0
\end{tabular}

\section{BULGULAR VE TARTIŞMA}

Farklı biçim dönemlerinin farklı karışım oranlarında yetiştirilen yem bezelyesi + tritikale karışımlarında tritikale bitki boyu ve yem bezelyesi ana sap uzunluğu değerleri bakımından biçim dönemi ve interaksiyonu istatistik açıdan önemli bulunmuştur (Çizelge 2).

Karışımların, tritikale bitki boyuna etkisi istatistiki yönden önemsiz bulunmuştur. Çizelge 2 incelendiğinde, biçim dönemi geciktikçe yem bezelyesi ana sap uzunluğu ve tritikale bitki boyu istatistiksel olarak önemli derecede artış meydana gelmiştir. Pek çok araştırıcı biçim döneminin gecikmesiyle birlikte bitki boylarının da artığını ifade etmişlerdir (Anwar ve ark., 2010; Kavut ve ark. 2014; Kır ve ark. 2018). Karışımdaki yem bezelyesi oranı artıkça yem bezelyesi ana sap uzunluğu ve tritikale bitki boylarında değişim tespit edilmiştir.

Farklı biçim dönemlerinin farklı karışım oranlarında yetiştirilen yem bezelyesi + tritikale karışımlarında yeşil ve kuru ot verimlerine etkisi önemli bulunmuştur (Çizelge 3 ).

Başaklanma döneminden süt olum dönemine geçince yeşil ve kuru ot veriminde istatistiksel olarak önemli derecede artış olduğu saptanmıştır. Yeşil ot verimi başaklanma döneminde ortalama $5395.13 \mathrm{~kg} / \mathrm{da}$ 'dan süt olum 
Çizelge 2. Araştırmada yer alan türlerin ana sap uzunluğu ve bitki boyu $(\mathrm{cm})$

\begin{tabular}{|c|c|c|c|c|c|c|c|}
\hline \multirow{3}{*}{\multicolumn{2}{|c|}{ Karışımlar }} & \multicolumn{3}{|c|}{ Yem Bezelyesi Ana Sap uzunluğu (cm) } & \multicolumn{3}{|c|}{ Tritikale Bitki Boyu (cm) } \\
\hline & & \multicolumn{3}{|c|}{ Biçim Dönemleri } & \multicolumn{3}{|c|}{ Biçim Dönemleri } \\
\hline & & Başaklanma & Süt Olum & Ortalama & Başaklanma & Süt Olum & Ortalama \\
\hline \multicolumn{2}{|l|}{$\% 100$ YB / T } & $102.67 d$ & $124.67 c^{1}$ & 113.67B* & $143.33 c$ & $155.33 b$ & 149.33 \\
\hline \multicolumn{2}{|c|}{$\% 25$ YB + \%75 T } & $129.33 b c$ & 136.00ab & 132.67A & $138.00 c$ & $163.00 a$ & 150.50 \\
\hline \multicolumn{2}{|c|}{$\% 50$ YB + \%50 T } & $131.67 \mathrm{bc}$ & $133.67 a-c$ & $132.67 \mathrm{~A}$ & $141.00 c$ & $145.00 c$ & 143.00 \\
\hline \multicolumn{2}{|c|}{$\% 75$ YB + \%25 T } & $130.33 b c$ & 143.33a & $136.83 \mathrm{~A}$ & $138.33 c$ & $155.67 a b$ & 147.00 \\
\hline \multicolumn{2}{|l|}{ Ortalama } & $123.50 \mathrm{~B}$ & $134.42 \mathrm{~A}^{+}$ & 128.96 & $140.17 b$ & $154.75 a$ & 147.46 \\
\hline \multirow{3}{*}{ LSD (0.05) } & Biçim dönemi & $4.87 * *$ & & & $3.77 * *$ & & \\
\hline & Karışımlar & $7.32 * *$ & & & ö.d & & \\
\hline & İnteraksiyon & $9.75^{* *}$ & & & $7.54 * *$ & & \\
\hline
\end{tabular}

*Aynı sütunda bulunan, baş harfi aynı olanların ortalaması, LSD testine göre $P \leq 0.05$ seviyesinde istatistiki olarak birbirinden farklı değildir.

${ }^{+}$Aynı satırda bulunan, baş harfi aynı olanların ortalaması, LSD testine göre $P \leq 0.05$ seviyesinde istatistiki olarak birbirinden farklı değildir.

${ }^{1}$ Aynı küçük harfe sahip, farklı uygulama-hasat zamanı kombinasyonlarının ortalaması, LSD testine göre P $\leq 0.05$ seviyesinde istatistiki olarak birbirinden farklı değildir.

Çizelge 3. Araştırmada yer alan türlerin yeşil ve kuru ot verimleri $(\mathrm{kg} / \mathrm{da})$

\begin{tabular}{|c|c|c|c|c|c|c|c|}
\hline \multirow{3}{*}{\multicolumn{2}{|c|}{ Karışımlar }} & \multirow{2}{*}{\multicolumn{3}{|c|}{$\begin{array}{l}\text { Yeşil Ot Verimi (kg/da) } \\
\text { Biçim Dönemleri }\end{array}$}} & Verimi $(\mathrm{kg} / \mathrm{da}$ & & \\
\hline & & & & & \multicolumn{3}{|c|}{ Biçim Dönemleri } \\
\hline & & Başaklanma & Süt Olum & Ortalama & Başaklanma & Süt Olum & Ortalama \\
\hline \multicolumn{2}{|l|}{$\% 100$ YB } & $1776.67 f$ & $3368.67 e^{1}$ & $2572.67 C^{*}$ & $364.33 f$ & $853.67 e$ & $609.00 \mathrm{C}$ \\
\hline \multicolumn{2}{|l|}{$\% 100 \mathrm{~T}$} & $6287.67 \mathrm{~cd}$ & 7416.67ab & $6852.17 \mathrm{~A}$ & $1836.00 d$ & 2789.00a & $2312.50 \mathrm{~A}$ \\
\hline \multicolumn{2}{|l|}{$\% 25$ YB + \%75 T } & 6998.67bc & 8109.00a & $7553.84 \mathrm{~A}$ & $1718.33 d$ & 2672.33ab & $2195.33 A B$ \\
\hline \multicolumn{2}{|l|}{$\% 50$ YB + \%50 T } & $6156.33 \mathrm{~cd}$ & 7835.67ab & $6996.00 \mathrm{~A}$ & $1700.33 d$ & $2517.00 b c$ & 2108.67AB \\
\hline \multicolumn{2}{|l|}{$\% 75$ YB + \%25 T } & $5756.33 d$ & $6135.00 \mathrm{~cd}$ & 5945.67B & $1641.00 \mathrm{~d}$ & $2326.00 c$ & 1983.50B \\
\hline \multicolumn{2}{|l|}{ Ortalama } & 5395.13B & $6573.00 \mathrm{~A}^{+}$ & 5984.07 & $1452.00 \mathrm{~B}$ & $2231.60 \mathrm{~A}$ & 1841.80 \\
\hline \multirow{3}{*}{ LSD (0.05) } & Biçim dönemi & $405.41 * *$ & & & $997.89 * *$ & & \\
\hline & Karışımlar & $729.49 * *$ & & & $208.68 * *$ & & \\
\hline & İnteraksiyon & $906.56^{* *}$ & & & $245.73 *$ & & \\
\hline
\end{tabular}

*Aynı sütunda bulunan, baş harfi aynı olanların ortalaması, LSD testine göre $P \leq 0.05$ seviyesinde istatistiki olarak birbirinden farklı değildir.

${ }^{+}$Aynı satırda bulunan, baş harfi aynı olanların ortalaması, LSD testine göre $P \leq 0.05$ seviyesinde istatistiki olarak birbirinden farklı değildir.

${ }^{1}$ Aynı küçük harfe sahip, farklı uygulama-hasat zamanı kombinasyonlarının ortalaması, LSD testine göre P $\leq 0.05$ seviyesinde istatistiki olarak birbirinden farklı değildir.

döneminde $6573.00 \mathrm{~kg} / \mathrm{da}$ 'a yükseldiği benzer şekilde kuru ot verimi de başaklanma döneminde ortalama 1452.00 kg/da'dan süt olum döneminde $2231.60 \mathrm{~kg} / \mathrm{da}$ 'a yükselmiştir. Pek çok araştırıcı biçim döneminin gecikmesi ile yeşil ve kuru ot veriminin artığını bildirmişlerdir. Örneğin, Aşık (2006) bezelye ve arpa karışımında yeşil ot veriminin arpanın sapa kalkma döneminde ortalama 1762.7 $\mathrm{kg} / \mathrm{da}$ 'dan arpa sarı olum döneminde $2303.5 \mathrm{~kg} / \mathrm{da}$ 'a yükseldiğini, benzer şekilde kuru madde veriminin arpanın sapa kalkma döneminde 322.9 kg/da'dan 944.9 kg/da'a yükseldiğini, Kavut ve ark. (2014) Macar fiğ + İtalyan çiminin karışım oranı ile hasat zamanı çalışmalarında, erken ilkbahar döneminde yeşil ot verimi ortalama $2398 \mathrm{~kg} /$ da'dan 4258 $\mathrm{kg} / \mathrm{da}$ 'a yükseldiğini, aynı şekilde kuru madde veriminin 350 kg/da'dan 927 kg/da yükseldiğini, Kır ve ark. (2018) Kırşehir koşullarında farklı oranlarda Macar fiğ + tahıl karışımlarında yeşil ot veriminin karınlanma döneminde $1240.8 \mathrm{~kg} / \mathrm{da}$ 'dan süt olum döneminde $1501.3 \mathrm{~kg} / \mathrm{da}$ 'a yükseldiğini aynı şekilde kuru ot veriminin karınlanma döneminde 304.6 $\mathrm{kg} / \mathrm{da}$ 'dan süt olum döneminde $490.2 \mathrm{~kg} / \mathrm{da}$ 'a yükseldiğini bildirmiştir. Elde edilen yeşil ve kuru ot verimleri değerleri, yukarıdaki araştırmacıların bazılarının bildirdiği verim değerleri aralığında, bazılarının bildirdiği değerlerden ise farklı bulunmuştur. Bu farklılığın kullanılan tür ve çeşitlerin yanında; karışım oranları, tohum miktarı, gübreleme, sulama, ekim sıklığı, iklim ve toprak özellikleri gibi birçok faktörden kaynaklandığı söylemek mümkündür.

Karışımların yeşil ve kuru ot verimlerine etkisi istatistiki yönden önemli olduğu tespit edilmiştir. En yüksek yeşil ve kuru ot verimleri istatistiki yönden farksız olan \%100 T, \%25 
YB + \%75 T ve \%50 YB + \%50 T elde edilirken, en düşük yeşil ve kuru ot verimleri ise \%100 YB elde edilmiştir (Çizelge 3 ). $\mathrm{Bu}$ durum, genel olarak tahılların baklagillere göre yüksek oranda kuru maddeyle birlikte daha yüksek karbonhidrat oranına sahip olmaları ve daha güçlü gelişme göstermelerinden kaynaklanmaktadır.

Buğdaygil ile baklagil karışımlarının yeşil ve kuru ot verimlerine etkisi ile ilgili yapılan çalışmalar incelendiğinde; Çelen ve ark. (2013) yaygın fiğ karışımlarında en yüksek yeşil ot verimini $5566 \mathrm{~kg} / \mathrm{da}$ ile \%60 yaygın fiğ + \%40 arpa karışımından elde edildiğini bildirmiştir. Yıldırım ve ParlakÖzaslan (2016) tritikale ile bezelye karışımlarında en yüksek yeşil ve kuru ot verimleri sırasıyla $1533.8 \mathrm{~kg} / \mathrm{da}$ ve 369.50 $\mathrm{kg} / \mathrm{da}$ ile $\% 75$ tritikale + \%25 bezelye karışımından elde edildiğini rapor etmiştir. Kır ve ark. (2018) Macar fiğ ile tritikale karışımında en yüksek yeşil ve kuru ot verimlerini sırasıyla $1649.7 \mathrm{~kg} / \mathrm{da}$ ve $489.1 \mathrm{~kg} / \mathrm{da}$ ile \%25 macar fiğ + \%75 tritikale karışımından elde edildiğini bildirmişlerdir. Elde edilen bulgular, yukarıdaki araştırıcıların sonuçlarıyla benzer ve farklılıklar olduğu tespit edilmiştir. Farklılıkların nedeni, araştırmaların farklı ekolojik koşullarda yürütülmesi yanında, karışımların değişik tür ile oranlarda oluşturulması ve yapılan uygulamalar olarak gösterilebilir.

Karışımların kuru ve yeşil otta yem bezelyesi oranına etkisi istatistiki yönden önemli bulunurken, biçim dönemleri ve biçim dönemi x karışım interaksiyonları kuru ve yeşil otta yem bezelyesi oranına etkisi önemsiz bulunmuştur.

Karışımda yer alan tritikale oranı azaldıkça kuru otta yem bezelyesi oranı ise \%4.74'ten \%14.39'a yeşil otta yem bezelyesi oranı da \%5.40'tan 14.61'e yükseldiği tespit edilmiştir (Çizelge 4). Pek çok araştırıcı karışımlarda yer alan baklagillerin oranının artması durumunda kuru ve yeşil otta da baklagillerin artığını bildirmişlerdir. Örneğin Aşık (2006) arpa ile bezelyesi karışımında yer alan arpanın oranı azaldığında yaş yem bezelyesi oranının tam tersi olarak \%13.04'ten \%43.38'e kuru yem bezelyesi oranı da benzer şekilde \%11.79'dan \%40.74'e yükseldiğini, Kır ve ark. (2018) Macar fiğ ile tritikale karışımında yer alan tritikale oranı azaldığında kuru otta macar fiğ oranının \%15.9'dan \%53.6'a yükseldiğini bildirmeleri bulgularımızı desteklemektedir.

Karışımların alan eşdeğerlik oranına etkisi istatistiksel olarak önemli olduğu tespit edilmiştir. En yüksek alan eşdeğerlik oranı istatistiksel olarak aynı gruba giren \%50 YB + \%50 T ve \%75 YB + \%25 T karışımlarından elde edilirken, en düşük ise \%25 YB + \%75 T karışımından elde edilmiştir (Çizelge 5).

Karışımların yalın ekilen türlere göre üstün olduklarını belirlemede kullanılan alan eşdeğerlik oranının 1'den büyük olması gerekmektedir (Albayrak, 2003; Karadağ ve Büyükburç, 2004). Elde edilen bir yıllık sonuçlara göre; alan eşdeğerlik oranının tamamı (1.08-1.30) 1'in üstündedir.

Çizelge 4. Araştırmada yer alan yem bezelyesinin kuru ve yeşil ottaki oranları (\%)

\begin{tabular}{|c|c|c|c|c|c|c|c|}
\hline \multirow{3}{*}{\multicolumn{2}{|c|}{ Karışımlar }} & \multicolumn{3}{|c|}{ Kuru Otta Yem Bezelyesi Oranı (\%) } & \multicolumn{3}{|c|}{ Yeşil Otta Yem Bezelyesi Oranı (\%) } \\
\hline & & \multicolumn{3}{|c|}{ Biçim Dönemleri } & \multicolumn{3}{|c|}{ Biçim Dönemleri } \\
\hline & & Başaklanma & Süt Olum & Ortalama & Başaklanma & Süt Olum & Ortalama \\
\hline \multicolumn{2}{|c|}{$\% 25$ YB + \%75 T } & 4.80 & 4.67 & $4.74 b *$ & 5.68 & 5.11 & $5.40 \mathrm{~b}$ \\
\hline \multicolumn{2}{|c|}{$\% 50$ YB + \%50 T } & 9.31 & 7.05 & $8.18 \mathrm{~b}$ & 10.34 & 7.57 & $8.95 b$ \\
\hline \multicolumn{2}{|c|}{$\% 75$ YB + \%25 T } & 14.05 & 14.73 & $14.39 a$ & 14.40 & 14.82 & $14.61 \mathrm{a}$ \\
\hline \multicolumn{2}{|l|}{ Ortalama } & 9.39 & 8.82 & 9.10 & 10.14 & 9.17 & 9.65 \\
\hline \multirow{3}{*}{ LSD (0.05) } & Biçim dönemi & ö.d & & & ö.d & & \\
\hline & Karışımlar & $3.55^{* *}$ & & & $3.88 * *$ & & \\
\hline & İnteraksiyon & ö.d & & & ö.d & & \\
\hline
\end{tabular}

*Aynı sütunda bulunan, baş harfi aynı olanların ortalaması, LSD testine göre $\mathrm{P} \leq 0.05$ seviyesinde istatistiki olarak birbirinden farklı değildir.

Çizelge 5. Araştırmada incelenen alan eşdeğerlik oranı (\%)

\begin{tabular}{|c|c|c|c|c|}
\hline \multirow{3}{*}{ Karışımlar } & & \multicolumn{3}{|c|}{ Alan Eşdeğerlik Oranı (\%) } \\
\hline & & \multicolumn{3}{|c|}{ Biçim Dönemleri } \\
\hline & & Başaklanma & Süt Olum & Ortalama \\
\hline$\% 25$ YB + \%75 T & & 1.10 & 1.07 & $1.08 b^{*}$ \\
\hline$\% 50$ YB + \%50 T & & 1.30 & 1.13 & $1.22 \mathrm{a}$ \\
\hline$\% 75$ YB + \%25 T & & 1.47 & 1.13 & $1.30 \mathrm{a}$ \\
\hline Ortalama & & 1.29 & 1.11 & 1.20 \\
\hline \multirow{3}{*}{ LSD (0.05) } & Biçim dönemi & ö.d & & \\
\hline & Karışımlar & $0.11^{*}$ & & \\
\hline & İnteraksiyon & ö.d & & \\
\hline
\end{tabular}

*Aynı sütunda bulunan, baş harfi aynı olanların ortalaması, LSD testine göre $\mathrm{P} \leq 0.05$ seviyesinde istatistiki olarak birbirinden farklı değildir. 
Rynolds ve ark. (1994) baklagil + buğdaygil karışımlarında baklagillerin karışımların biomasını yükselterek verimi arttırdığını, Albayrak ve Ekiz (2000)'de karışımları oluşturan türlerin iyi seçilmesi durumunda karışımların yalın ekimlere göre daha verimli olduklarını vurgulamışlardır. Bunlara ek olarak Rakeih ve ark. (2010) ve Dahmardeh (2013)'de karışık ekimlerin yalın ekimler göre üstün olduklarını bildirmişlerdir.

\section{SONUÇ}

Diyarbakır ve benzer ekolojilerde yetiştirilmesi düşünülen yem bezelyesi + tritikale karışımları için yeşil ve kuru ot verimleri, karışım oranları ile biçim dönemleriyle birlikte değerlendirildiğinde; en yüksek verimin elde edildiği \%25 YB + \%75 T karışımı ve karışımdaki tritikalenin süt olum döneminde hasat edilmesi diğer uygulamalara kıyasla daha üstün bulunmuştur. Ancak, bölgede hangi karışım oranı ile biçim dönemlerinin daha uygun olacağı konusunda daha net olarak tavsiye yapılabilmesi için araştırmanın en az 1 yıl daha yürütülmesi daha uygun olacaktır.

\section{TEŞEKKÜR}

$\mathrm{Bu}$ çalışma Tarımsal Araştırmalar ve Politikalar Genel Müdürlüğü (TAGEM) tarafından TAGEM/17A07/P7/004 nolu proje ile desteklenmiştir. Desteklerinden dolayı TAGEM'e teşekkürlerimizi sunarız.

\section{KAYNAKLAR}

Albayrak S, Ekiz H (2000) Yapay Mer'aların Kurulması ve Önemi. Türk-Koop. Ekin Dergisi, (13): 95-99.

Albayrak S (2003) Ankara Ekolojik Koşullarında Yapay Mera Kurulması Üzerine Bir Araştırma. Doktora Tezi, Ankara Üniversitesi, Ankara.

Anonim (2019) Meteoroloji Genel Müdürlüğü. Ankara

Anwar A, M Ansar, M Nadeem, G Ahmad, S Khan, A Hussain (2010) Performance of Non-Traditional Winter Legumes With Oats for Forage Yield Under Rainfed Conditions. Journal of Agriculture Research, 48(2): 171-179.

Aşık F (2006) Bezelye (Pisum sativum L.) ve Arpa (Hordeum vulgare L.) Karışımlarında Karışım Oranları Ve Biçim Zamanlarının Otun Verimi İle Kalitesi Üzerine Etkileri. Yüksek Lisans Tezi, Uludağ Üniversitesi, Bursa.

Çelen E, Demiroğlu Topçu, G, Fıçıcı GS (2013) Adi fiğ (Vicia sativa L.) + Arpa (Hordeum vulgare L.) Karışımında Uygun Karışım Oranının Saptanması Üzerine Bir Araştırma. Türkiye 10. Tarla Bitkileri Kongresi, 10-13 Eylül 2013, Konya, 359-361.

Dahmardeh M (2013) Intercropping Barley (Hordeum vulgare L.) and Lentil (Lens culinaris L.) Yield and Intercropping Advantages. Journal of Agricultural Science, 5 (4): 209-215.

Ghanbari-Banjar A, Lee HC (2003) Intercropped Wheat (Triticum aestivum L.) and Bean (Vicia faba L.) as a Whole-crop Forage: Effect of Harvest Time on Forage Yield and Quality. Grass and Forage Science 58:28-36.

Işık Ş, Ateş S, Keles G, İnal F, Güneş A (2013) Macar Fiği, Tritikale, Macar Fiği+Tritikale Bitkilerinin Farklı Gelişim Dönemlerindeki Verim Ve Besin Madde İçerikleri.
SEYDOŞOĞLU S, GELIR G, AYANA ÇAM B

Türkiye 10. Tarla Bitkileri Kongresi, 10-13 Eylül 2013, Konya, 81-86.

Kalaycı M (2005) Örneklerle Jump Kullanımı ve Tarımsal Araştırma İçin Varyans Analizi Modelleri. Anadolu Tarımsal Araştırma Enstitüsü Müdürlüğü Yayınları, yayın no:21

Karadağ Y, Büyükburç U (2004). Forage Qualities, Forage Yields and Seed Yields of Some Legume-Triticale Mixtures Under Rainfed Conditions, Acta Agriculturae Scandinavica 54(3):140-148.

Kavut YT, Geren H, Soya H, Avcıoğlu R, Kır B (2014). Karışım Oranı ve Hasat Zamanlarının Bazı Yılıı Baklagil Yembitkileri ile İtalyan Çimi Karışımlarının Kışlık Ara Ürün Performansına Etkileri. Ege Üniversitesi Ziraat Fakültesi Dergisi, 51(3): 279-288.

Kır H (2014) Kırşehir Koşullarında Farklı Biçim Zamanları ve Karışım Oranlarının Macar Fiği Tahıl Karışımlarının Verim Ve Kalitesi Üzerine Etkileri. Doktora Tezi, Gaziosmanpaşa Üniversitesi, Tokat.

Kır H, Karadağ Y, Yavuz T (2018) The Factors Affecting Yield And Quality of Hungarian Vetch+Cereal Mixtures In Arid Environmental Conditions. Fresenius Environmental Bulletin 27(12A):9049-9059.

Kocer A, Albayrak S (2012) Determination of Forage Yield and Quality of Pea (Pisum sativum L.) Mixtures With Oat And Barley. Turkish Journal of Field Crops, 17(1): 96-99.

Mariotti M, Masoni A, Ercoli L, Arduini I (2009) Above-And Below-Ground Competition Between Barley, Wheat, Lupin And Vetch in A Cereal And Legume Intercropping System. Grass and Forage Science. 64: 401-412.

Mihailovic V, Mikic A, Kobiljski B, Cupina B, Antanasovic S, Krstic D, Katanski S (2011) Intercropping Pea With Eight Cereals For Forage Production. Pisum Genetics, 43: 33-35.

Pereira-Crespo S, Fernández-Lorenzo B, Valladares J, González-Arráez A, Flores G (2010) Effects of Seeding Rates And Harvest Date on Forage Yield And Nutritive Value Of Pea-Triticale Intercropping. Options Méditerranéennes, $A$, (92):215-218.

Rakeih N, Kayyal H, Larbi A, Habib N (2010) Forage Yield and Competition Indices of Triticale and Barley Mixed Intercropping with Common Vetch and Grasspea in the Mediterranean Region. Jordan Journal of Agricultural Sciences, 6 (2):194-207.

Rynolds MP, Sayre KD, Vivor HE (1994) Intercropping Wheat And Barley With N- Fixing Legume Species: A Method For Improving Ground Cover, N-Use Efficiency And Productivity in Low input Systems. Journal of Agricultural Science, 123(2): 175-183.

Yıldırım S, Parlak-Özaslan A (2016) Tritikale ile Bezelye, Bakla ve Fiğ Karışım Oranlarının Belirlenerek Yem Verimi ve Kalitesine Etkileri. Çanakkale Onsekiz Mart Üniversitesi Ziraat Fakültesi Dergisi. 4 (1): 77-83. 
